\title{
Dental Student Skills in Matching Radiographs for Forensic Identification and in Forensic Knowledge
}

\author{
Mona Sivaneri $\left(\mathrm{D},{ }^{1}\right.$ R. Constance Wiener $\left(\mathrm{D},{ }^{2}\right.$ \\ Alcinda K. Trickett Shockey ${ }^{(D)}{ }^{3}$ and Christopher Waters ${ }^{4}$ \\ ${ }^{1}$ School of Medicine, West Virginia University, 104a Health Sciences Addition, P.O. Box 9415, Morgantown, WV 26506, USA \\ ${ }^{2}$ Department of Dental Practice and Rural Health, School of Dentistry, West Virginia University, 104a Health Sciences Addition, \\ P.O. Box 9415, Morgantown, WV 26506, USA \\ ${ }^{3}$ Department of Dental Hygiene, West Virginia University, Health Sciences Center North, Room 1192A, Morgantown, \\ West Virginia 26506, USA \\ ${ }^{4}$ Department of Dental Research, School of Dentistry, West Virginia University, 106 a Health Sciences Addition, \\ P.O. Box 9448, Morgantown, WV 26506, USA
}

Correspondence should be addressed to R. Constance Wiener; rwiener2@hsc.wvu.edu

Received 5 December 2017; Revised 19 February 2018; Accepted 28 February 2018; Published 2 April 2018

Academic Editor: Terrence M. Shaneyfelt

Copyright (C) 2018 Mona Sivaneri et al. This is an open access article distributed under the Creative Commons Attribution License, which permits unrestricted use, distribution, and reproduction in any medium, provided the original work is properly cited.

\begin{abstract}
Purpose and Objectives. Dental and dental hygiene curricula must meet the core competencies established by the American Dental Association Commission on Dental Accreditation. As a result, there is limited time to expose students to the research and knowledge associated with additional important topics, such as dental forensics. The purpose of this research is to assess dental forensic knowledge and dental forensic radiographic skills of dental students. Methods. Ten radiographs of extracted permanent maxillary molars were exposed. One of the teeth was heat-altered to $600^{\circ} \mathrm{F}\left(315.6^{\circ} \mathrm{C}\right)$ for 15 minutes and then was radiographed. The 11 radiographs were presented to 152 dental students who were asked to match the radiograph of the heat-altered tooth to the original radiograph of that tooth. Students were also asked to respond to a 10-question survey about dental forensic knowledge. Results. Most $(92.1 \%)$ students matched the heat-altered tooth's radiograph with the original radiograph. Five survey questions had at least $70 \%$ of the respondents with correct responses. There were no statistically significant differences by dental class status or sex. Conclusion. Although dental students were competent in matching radiographs, there remains a need for more knowledge about dental forensics.
\end{abstract}

\section{Introduction}

Teeth, when compared to bone, are the strongest tissues of the human body [1]. Drastic changes in bone properties during burning can cause great difficulties in forensic identification. Bone is subject to heat-induced shrinkage and deformations that alter morphological indicators that are critical for victim identification [2]. However, when teeth are subjected to heat, teeth are much less susceptible to destruction than bone [1].

Teeth are able to withstand a significant amount of heat before undergoing drastic change. Additionally, the anatomy of human teeth, when compared to other species, is unique and useful for human identification. When dental restorations are present, the teeth are useful for specific human identifications, if existing dental radiographs are available [1].

When a massive disaster occurs, there is one task that must be completed to assure closure for the families of the victims, that is, victim identification. In disasters with thousands of victims, the most common records used and available for identification are dental records [1], particularly dental radiographs. Other new and innovative techniques, such as DNA technology in forensic dentistry, are also becoming very important in human identification [3]. However, DNA is heat-labile, whereas, teeth, as well as restorations, are able to withstand a significant amount of heat [4]. 
The foundation of identification through dental remains begins by comparing the teeth, as well as the occlusion, with available dental records [4]. Comparing ante-mortem and postmortem dental radiographs is the most dependable method of determining an individual's identification from dental remains [4]. Many other techniques are being developed in dental forensics to provide higher scientific certainty of identification from heat-altered teeth. These applications include the use of cone-beam computed tomography [5], the identification of restorative dental materials through microscopy and elemental analyses [6], and computer algorithms of ante-mortem and postmortem dental records [7]. In a recent reliability study, raters using cone-beam computed tomography imaging techniques were able to make accurate visual comparisons with ante-mortem radiographs [8]. In cases where ante-mortem records are not currently available, a forensic dentist can create a postmortem dental profile to be saved for any potential future availability or disclosure of ante-mortem records [9].

With all of these advancing technologies in forensic identification, there is still a critical need for dental professionals to be able to make comparisons of radiographs in a patient's chart or electronic record and radiographs of victims taken after a disaster. Dental students need to learn how to make comparisons between ante-mortem and postmortem radiographs. The aim of this research was to assess dental student knowledge about dental forensics and to evaluate dental student skills in comparing radiographs. Our central hypothesis is that there is no difference in the ability of dental students at each level of their education in making comparisons of radiographs and in their knowledge of dental forensics.

\section{Materials and Methods}

West Virginia University Institutional Review Board approved this study (protocol number 1607188209). Ten extracted permanent maxillary molars were selected, autoclaved, measured, photographed, and digitally radiographed. One of the permanent maxillary molars was placed into a dental burn-out oven and heat-altered to $600^{\circ} \mathrm{F}\left(315.6^{\circ} \mathrm{F}\right)$, the temperature at which changes in teeth due to heat exposure occur $[10,11]$ for 15 minutes. The heat-altered tooth was then digitally radiographed.

A ten-question dental forensic knowledge survey was created for first-year (D1), second-year (D2), and thirdyear (D3) dental students from one university. It should be noted that the D1 student curricula include 16 weekly 1hour dental anatomy lectures and 16 weekly 3-hour dental anatomy laboratory sessions in the fall of their first year. Dental radiology is introduced in the second year and D2 students receive 32 weekly 1-hour dental radiology lectures and 2-hour dental radiology rotations as assigned throughout the year. A specific course in dental forensics is not included in the curricula; however, the skills from the dental anatomy course and the dental radiology course are hypothesized to transfer to dental forensic skills. The dental forensic knowledge survey questions (which were the same for D1,
TABLE 1: Characteristics of the dental student participants.

\begin{tabular}{lcc}
\hline & Frequency $(N)$ & $\%$ \\
\hline Sex & 70 & \\
Male & 79 & 46.1 \\
Female & 3 & 52.0 \\
Missing & & 2.0 \\
Race & 121 & \\
Non-Hispanic white & 28 & 79.6 \\
Other & 3 & 18.5 \\
Missing & & 2.0 \\
Class rank & 50 & \\
$\quad$ First-year dental students & 46 & 32.9 \\
Second-year dental students & 56 & 30.3 \\
Third-year dental students &
\end{tabular}

D2, and D3) required Likert-style responses (strongly agree, agree, neutral, disagree, and strongly disagree).

The survey also contained a simulated case utilizing the radiographs of the distractor teeth and the heat-altered tooth: someone had been in a house fire that burned at 600 degrees Fahrenheit and a heat-altered tooth was found. The participants were asked to match the radiograph of the heataltered tooth with one of the radiographs from among 10 radiographs given (Figure 1).

The eligibility criteria for this study were that students were registered as dental students and at least age 18 years. This research was conducted midway through the fall semester for the D1, D2, and D3 students.

2.1. Outcomes. The primary outcome was the ability to match the heat-altered radiograph with the radiograph of the tooth prior to the heat alteration. We were secondarily interested in determining the number of correct responses to the other dental forensic knowledge questions presented on the survey.

2.2. Data Analysis. Frequency analyses of correct responses to the survey questions were conducted. Additionally, the answers were collapsed into two categories: true (which included strongly agree and agree); false (which included neutral, disagree, and strongly disagree). Determinations for categorical differences by D1/D2/D3 status and by sex were conducted using Chi square testing. Significance was established a priori as results with $P<0.05$. SPSS Statistics $24^{\circledR}$ (IBM, ${ }^{\circledR}$ Armonk, NY, USA) was used in the data analysis.

\section{Results}

There were 152 students who participated in the study; $52 \%$ were female. There were 50 D1 students, 46 D2 students, and 56 D3 students. Most (79.6\%) were non-Hispanic white (Table 1).

The primary outcome was the matching of the radiograph of the heat-altered tooth from among 10 radiographs, including the matching radiograph. There were $92.1 \%$ of participants who responded correctly (Table 2 ). 


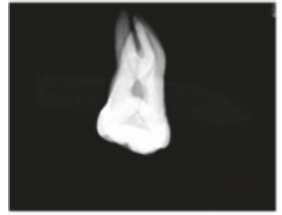

Heat-altered

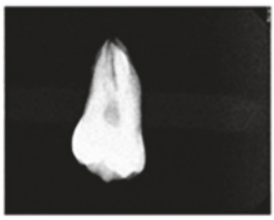

Radiograph 5

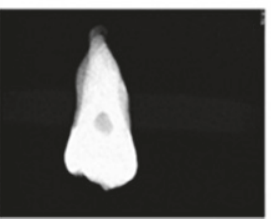

Radiograph 10

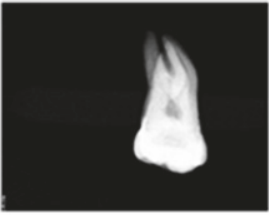

Radiograph 1 matches heat-altered tooth

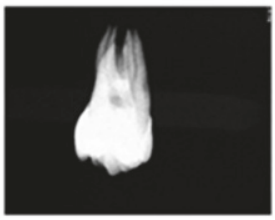

Radiograph 6

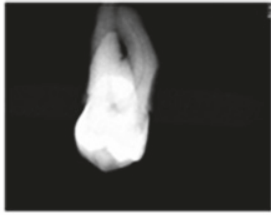

Radiograph 2

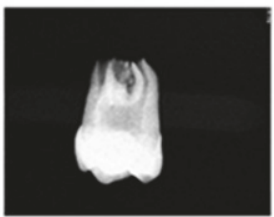

Radiograph 7

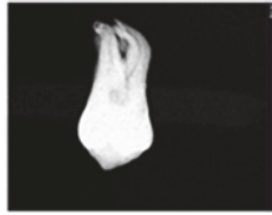

Radiograph 3

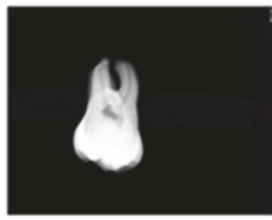

Radiograph 8

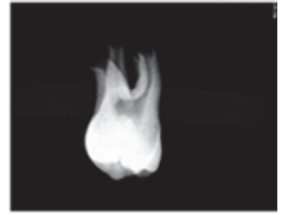

Radiograph 4

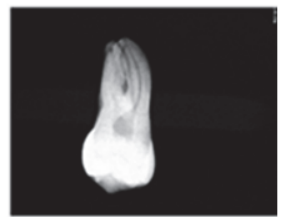

Radiograph 9

FIGURE 1: Radiographs presented in the survey.

Responses to the dichotomized true/false forensic knowledge assessment survey questions are presented in column 1 of Table 2. Responses by strongly agree/agree/neutral/ disagree/strongly disagree are also presented in Table 2 .

The dichotomized response with the fewest correct choices $(25.77 \%$ correct) was the true statement that the shape of palatal rugae remains consistent and is a reliable forensic marker. The dichotomized response with the most correct choices $(86.8 \%)$ was the true statement that altering original dental images may result in inaccurate identifications should a disaster requiring dental forensics occur.

Not presented in tabular form are the results of the comparison of D1/D2/D3 status and percentage of correct dichotomized responses as there were no significant differences among the classes in any of the responses. Similarly, not presented in tabular form are the results based on sex as there were no significant differences between male and female students in any of the responses. Of the 10 questions provided, at least $70 \%$ of the students responded accurately to five questions when the responses were dichotomized.

\section{Discussion}

The researchers of this study assessed D1/D2/D3 students' dental forensic knowledge and the application of that knowledge to a forensic scenario. The vast majority (92.1\%) of the participants (at all levels of their education) were able to match a radiograph of a tooth altered by extreme heat to its original radiograph from among 10 radiograph options. There were no significant differences among D1/D2/D3 students in the matching of the radiographs. The ability to determine anatomic characteristics to make the match is a tribute to their knowledge of dental anatomy and the early presentation of the dental anatomy course in the first semester of the curricula. Despite the students being at differing levels in their education, the vast majority was able to evaluate dental structures on radiographs to make an accurate match determination from among presented radiographs. The images were not troublesome to the students.

However, as dental forensics is not a specific course in the curricula, there was a lack of knowledge of specific items presented to the students in the rest of the survey. Results from those survey questions indicate that there is a need to address the emerging knowledge associated with dental forensics. Dental forensics is a field in which new knowledge, procedures, technology, and applications are rapidly being developed. It is important that such knowledge is clinically translated. Clinical translation involves the movement from unawareness to use of evidence. Therefore, although the ability to match radiographs is of paramount importance in identification, there is also a need to know about the advances and techniques in dental forensics [12].

4.1. Comparative Studies. This study is innovative, and, as such, there are few other studies in the literature with which to compare the knowledge of dental students about dental forensics. A somewhat similar study involved 10 dental students in Denmark. Researchers learned that the students were able to match human skulls with radiographs; however, half of the students in that study made false positive matches [13]. In another study that was a survey of 273 dental hygiene students, $93 \%$ indicated that they had not received formal 
TABLE 2: Survey responses.

\begin{tabular}{|c|c|c|c|c|c|c|}
\hline & $\begin{array}{c}\text { (Correct } \\
\text { dichotomized } \\
\text { response) and \% } \\
\text { correct }\end{array}$ & $\begin{array}{l}\text { Strongly } \\
\text { agree }\end{array}$ & Agree & Neutral & Disagree & $\begin{array}{l}\text { Strongly } \\
\text { disagree }\end{array}$ \\
\hline $\begin{array}{l}\text { (1) Did the student match the correct original } \\
\text { radiograph? }\end{array}$ & $92.1 \%$ & & & & & \\
\hline $\begin{array}{l}\text { (2) If a single rooted tooth had an endodontic } \\
\text { procedure, is it possible to match ante and } \\
\text { post-mortem radiographs. }\end{array}$ & (True) $74.3 \%$ & (21) $13.8 \%$ & (92) 60.5\% & (23) $15.1 \%$ & (12) $7.9 \%$ & (2) $1.3 \%$ \\
\hline $\begin{array}{l}\text { (3) The shape of palatal rugae remain consistent } \\
\text { and are reliable forensic markers. }\end{array}$ & (True) $25.7 \%$ & (9) $5.9 \%$ & (30) $19.7 \%$ & (34) $22.4 \%$ & (65) $42.8 \%$ & (13) $8.6 \%$ \\
\hline $\begin{array}{l}\text { (4) Forensic odontology means "dealing with the } \\
\text { time of death." }\end{array}$ & (False) $85.5 \%$ & (5) $3.3 \%$ & (16) $10.5 \%$ & (23) $15.1 \%$ & (67) $44.1 \%$ & (39) $25.7 \%$ \\
\hline $\begin{array}{l}\text { (5) } 2 \mathrm{D} \text { bar codes are most commonly used in } \\
\text { dentures of people with Parkinson's and } \\
\text { neurodegenerative diseases. }\end{array}$ & (True) $44.7 \%$ & (11) $7.2 \%$ & (57) $37.5 \%$ & (65) $42.8 \%$ & (14) $9.2 \%$ & (4) $2.6 \%$ \\
\hline $\begin{array}{l}\text { (6) Mesiodistal width of incisors can discriminate } \\
\text { between male and females and are routinely used } \\
\text { in court as evidence of sex. }\end{array}$ & (False) $70.4 \%$ & (9) $5.9 \%$ & (36) $23.7 \%$ & (29) $19.1 \%$ & (60) $39.5 \%$ & (18) $11.8 \%$ \\
\hline $\begin{array}{l}\text { (7) Altering original dental images may result in } \\
\text { inaccurate identifications should a disaster } \\
\text { requiring dental forensics occur. }\end{array}$ & (True) $86.8 \%$ & (70) $46.1 \%$ & (62) $40.8 \%$ & (14) $9.2 \%$ & (4) $2.6 \%$ & (2) $1.3 \%$ \\
\hline $\begin{array}{l}\text { (8) }{ }^{14} \text { Carbon dating of teeth can be used to } \\
\text { determine a person's age within an error of } \pm 1.75 \\
\text { years. }\end{array}$ & (True) $62.5 \%$ & (14) $9.2 \%$ & (81) $53.3 \%$ & (48) $31.6 \%$ & (7) $4.6 \%$ & (2) $1.3 \%$ \\
\hline $\begin{array}{l}\text { (9) The lightest striae of Retzius (the neonatal } \\
\text { line) is associated with a stress of teething. }\end{array}$ & (False) $65.8 \%$ & (11) $7.2 \%$ & (40) $26.3 \%$ & (48) $31.6 \%$ & (44) $28.9 \%$ & (8) $5.3 \%$ \\
\hline $\begin{array}{l}\text { (10) In adult radiographs, physiologic changes can } \\
\text { be seen as widening of pulp area. }\end{array}$ & (False) $63.8 \%$ & (18) $11.8 \%$ & (36) $23.7 \%$ & (17) $11.2 \%$ & (43) $28.3 \%$ & (37) $24.3 \%$ \\
\hline $\begin{array}{l}\text { (11) Use of third molar development as a legal } \\
\text { landmark of age is valid. }\end{array}$ & (False) $70.4 \%$ & (8) $5.3 \%$ & (33) $21.7 \%$ & (32) $21.1 \%$ & (48) $31.6 \%$ & (27) $17.8 \%$ \\
\hline
\end{tabular}

Note. True: strongly agree or agree; false: neutral, disagree, or strongly disagree.

education in disaster preparedness but viewed themselves as professionals who could provide many tasks in disaster response [14].

4.2. Future Research. There is a need for future research in dental and dental hygiene programs involving forensics. Researchers reported that $58 \%$ of respondents from the nation's dental schools with forensics programs had primarily didactic courses [15]. Several dental schools, with forensics curricula in place (discussed by Stoeckel et al., 2007 [16], and Hermsen and Johnson, 2012 [17]), included elective or required courses with hands-on exercises. Future research is also needed concerning the possible inclusion of dental forensics on a national level as a measurable competency by the American Dental Association/American Dental Hygiene Association/Commission on Accreditation.

4.3. Strengths and Weaknesses. This study is important in understanding the need for dental education relating to dental forensics. One of its strengths is the number of students who participated; each of the survey questions had at least a $97 \%$ completion rate. The study size was large enough to power the study. A weakness of the study was that only one school, with a student population predominately
non-Hispanic white, was used for the study. Therefore, racial/ethnic differences were not included. In addition, as the age of the students was predominately 22-26 years, age was not included in the study.

\section{Conclusion}

Dental forensics is an important consideration for dental curricula. The healthcare workforce of the US is only second in size to the US military; therefore, healthcare professionals are important as potential responders to terrorism, public health emergencies, and victim identification [18]. Preparation is essential. In this study, dental students were successful in matching a dental radiograph of a heat-altered tooth and its original radiograph. However, there is a need for current and emerging information about dental forensics.

\section{Disclosure}

The content is solely the responsibility of the authors and does not necessarily represent the official views of the National Institutes of Health or the Department of State. Ms. Mona Sivaneri, as a M.S. degree student in Health Sciences, presented initial results of the study as a poster at the 2017 West 
Virginia University Van Liere and Research Day for students and faculty [19].

\section{Conflicts of Interest}

The authors declare that there are no conflicts of interest regarding the publication of this article.

\section{Acknowledgments}

Drs. R. Constance Wiener and Alcinda K. Trickett Shockey received research support by the National Institute of General Medical Sciences of the National Institutes of Health under Award no. U54GM104942.

\section{References}

[1] E. Auerkari, "Recent trends in dental forensics," Indonesian Journal of Legal and Forensic Sciences, vol. 1, no. 1, p. 12, 2008.

[2] K. Imaizumi, "Forensic investigation of burnt human remains," Research and Reports in Forensic Medical Science, vol. 5, pp. 6774, 2015.

[3] R. H. A. Da Silva, A. Sales-Peres, R. N. De Oliveira, F. T. De Oliveira, and S. H. D. C. Sales-Peres, "Use of DNA technology in forensic dentistry," Journal of Applied Oral Science, vol. 15, no. 3, pp. 156-161, 2007.

[4] S. L. Avon, "Forensic odontology: The roles and responsibilities of the dentist," Journal of the Canadian Dental Association, vol. 70, no. 7, pp. 453-458, 2004.

[5] D. A. Trochesset, R. B. Serchuk, and D. C. Colosi, "Generation of Intra-oral-like Images from Cone Beam Computed Tomography Volumes for Dental Forensic Image Comparison," Journal of Forensic Sciences, vol. 59, no. 2, pp. 510-513, 2014.

[6] A. S. Soon, M. A. Bush, and P. J. Bush, "Complex layered dental restorations: Are they recognizable and do they survive extreme conditions?" Forensic Science International, vol. 254, pp. 1-4, 2015.

[7] B. J. Adams and K. W. Aschheim, "Computerized dental comparison: A critical review of dental coding and ranking algorithms used in victim identification," Journal of Forensic Sciences, vol. 61, no. 1, pp. 76-86, 2016.

[8] T. D. Ruder, Y. A. Thali, S. N. A. Rashid et al., "Validation of post mortem dental CT for disaster victim identification," Journal of Forensic Radiology and Imaging, vol. 5, pp. 25-30, 2016.

[9] I. A. Pretty and D. Sweet, "A look at forensic dentistry - Part 1: The role of teeth in the determination of human identity," British Dental Journal, vol. 190, no. 7, pp. 359-366, 2001.

[10] PL. Walker, KW. Miller, and R. Richman, "temperature and oxygen availability: and experimental study of the effects of environmenta conditions on the color and organic content of cremated bone," in The Analysis of Burned Human Remains, J. J. Beach, A. B. Bontrager, E. N. Chapman et al., Eds., chapter 7, pp. 129-135, Academic Press, Cleveland, Ohio, USA, 2008.

[11] J. J. Beach, N. V. Passalacqua, and E. N. Chapman, "Heatrelated changes in tooth color: temperature versus duration of exposure," The Analysis of Burned Human Remains, pp. 137-144, 2008.

[12] A. Basit, S. M. Shah, R. A. Jameel, and M. Azeem, "Evaluation of dental record keeping at Hamdard University Dental Hospital," Pakistan Oral \& Dental Journal, vol. 36, no. 1, pp. 38-41, 2016.
[13] A. Wenzel, A. Richards, and J. Heidmann, "Matching simulated antemortem and postmortem dental radiographs from human skulls by dental students and experts: Testing skills for pattern recognition," Journal of Forensic Odonto-Stomatology, vol. 28, no. 1, pp. 5-12, 2010.

[14] B. T. Bradshaw, A. P. Bruhn, T. L. Newcomb, B. D. Giles, and K. Simms, "Disaster preparedness and response: a survey of US Dental Hygienists," JDH, vol. 90, no. 5, pp. 313-322, 2016.

[15] E. E. Herschaft and R. H. Rasmussen, "The teaching of forensic dentistry: a status report.," Journal of Dental Education, vol. 42, no. 9, pp. 532-536, 1978.

[16] D. C. Stoeckel, P. J. Merkley, and J. McGivney, "Forensic dental training in the dental school curriculum," Journal of Forensic Sciences, vol. 52, no. 3, pp. 684-686, 2007.

[17] K. P. Hermsen and J. D. Johnson, "A model for Forensic dental education in the predoctoral dental School curriculum," Journal of Dental Education, vol. 76, no. 5, pp. 553-561, 2012.

[18] D. Markenson, C. DiMaggio, and I. Redlener, "Preparing health professions students for terrorism, disaster, and public health emergencies: Core competencies," Academic Medicine: Journal of the Association of American Medical Colleges, vol. 80, no. 6, pp. 517-526, 2005.

[19] M. Sivaneri, "Dental Student Forensic Knowledge and Skills, Item 2017 West Virginia University Van Liere and Research Day, Group 149, Board 133," http://webcache.googleusercontent.com/ search?q=cache:qxpHr-UUIjIJ:www.hsc.wvu.edu/media/8992/ poster-presentations-board-assignments.xlsx+\&amp;cd=1\&amp; $h \mathrm{l}=$ en\&amp;ct=clnk\&amp;gl=eg. 


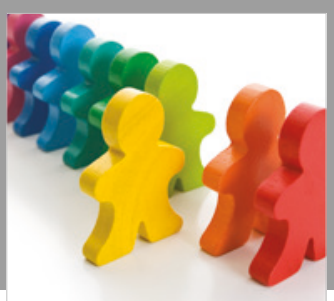

Autism

Research and Treatment
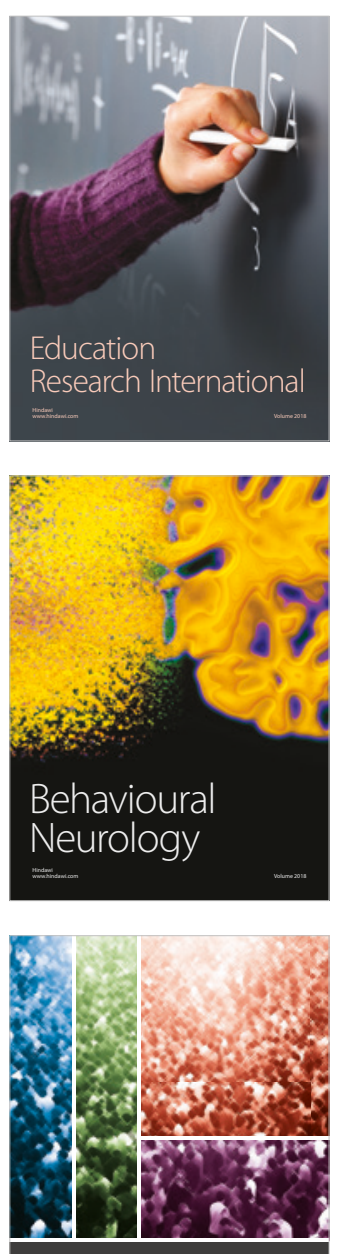

International Journal of

Population Research

$\underline{-m}$

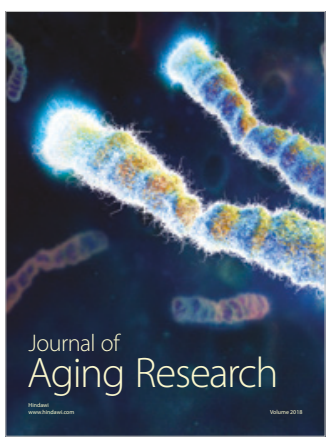

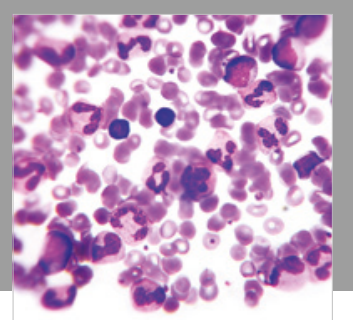

Pathology

Research International$$
=
$$

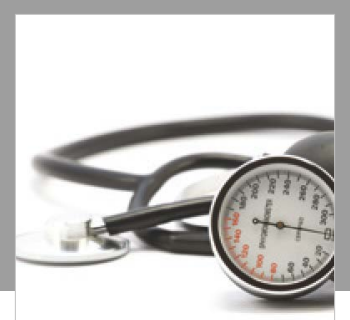

Nursing

Research and Practice

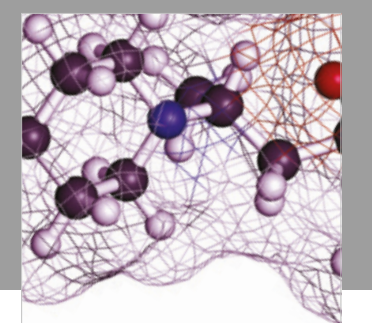

Pain

Research and Management

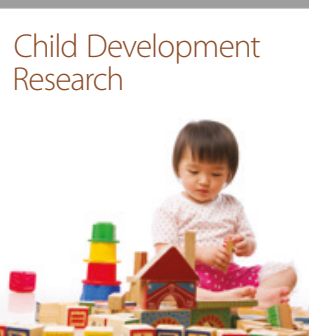

बाD

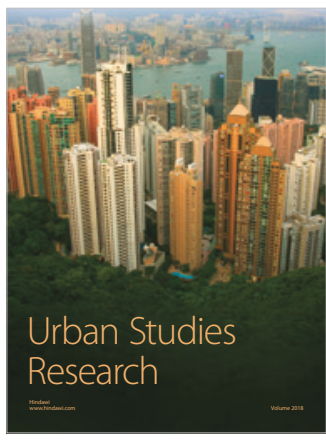

\section{Hindawi}

Submit your manuscripts at

www.hindawi.com
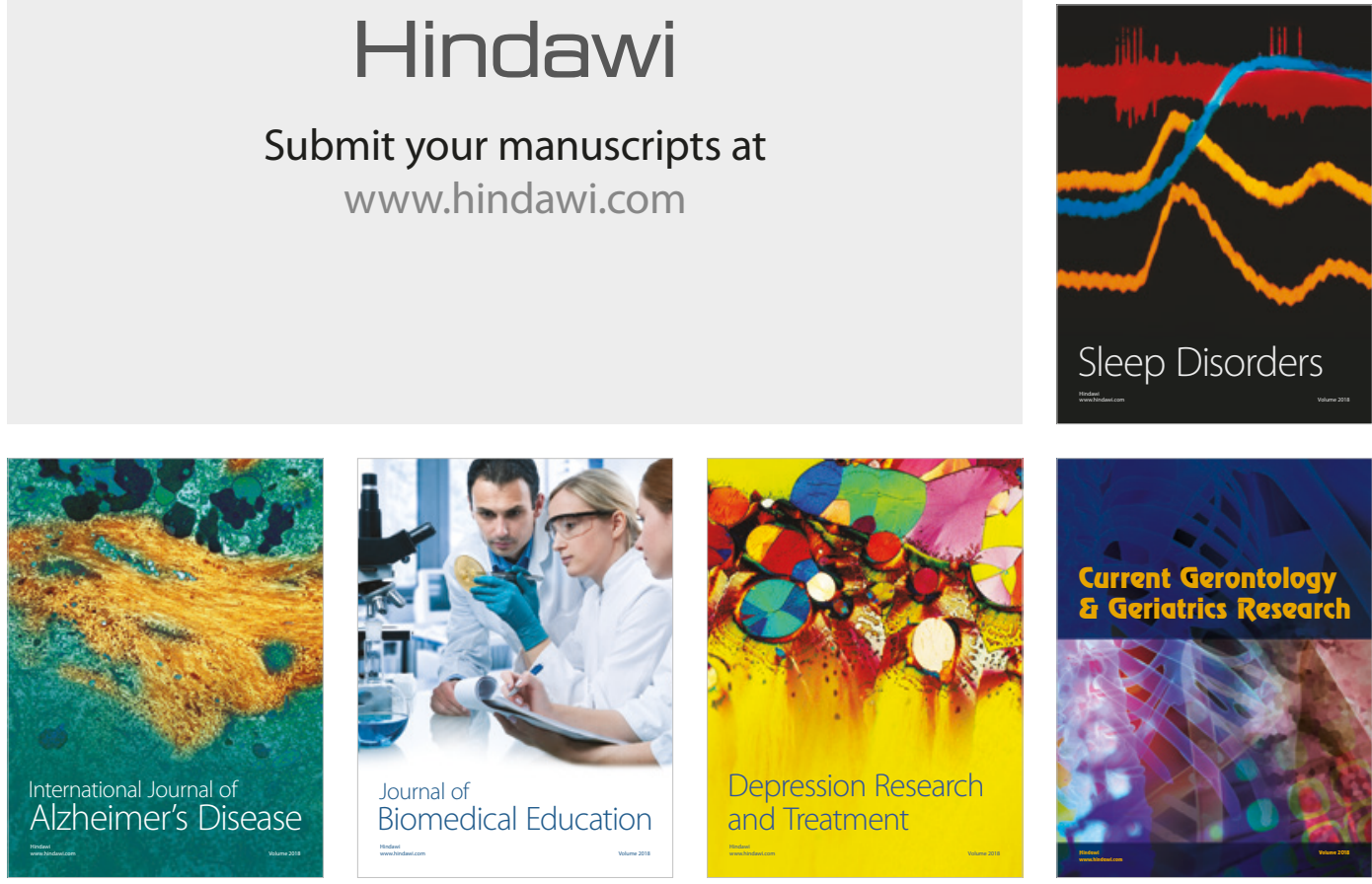

Journal of

Biomedical Education

$=$

smman

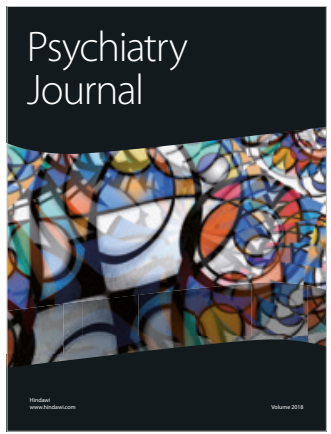

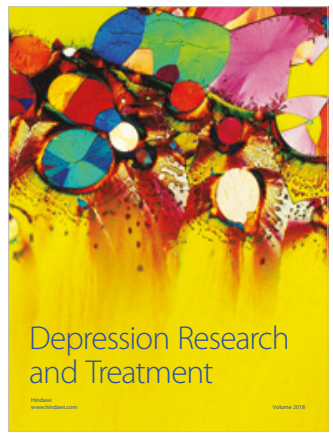
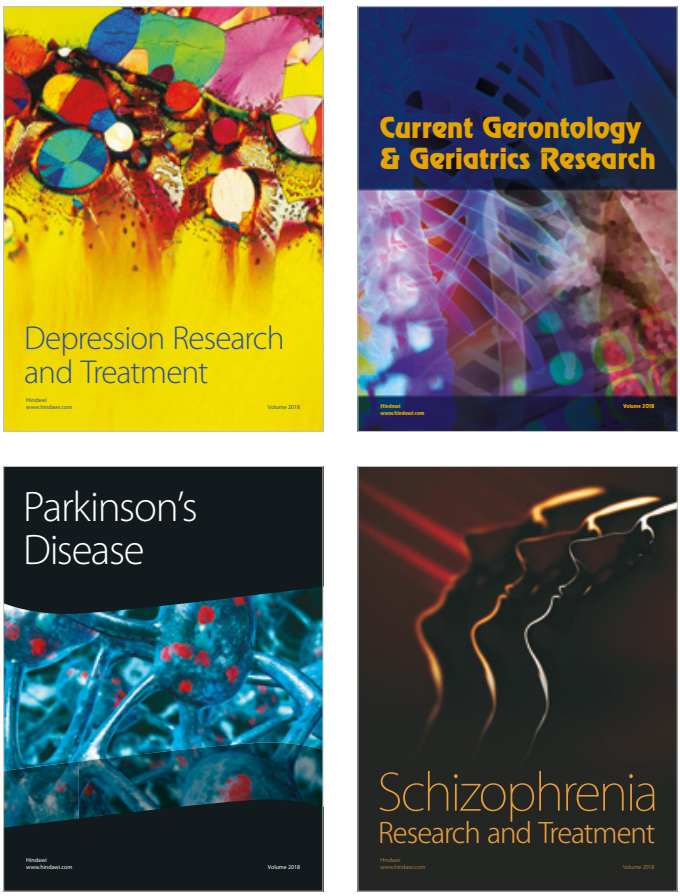